\title{
THE SIGNIFICANCE OF HERC5, IFIH1, SAMD4, SEMA3A AND MCTP1 GENES EXPRESSION IN RESISTANCE TO CYTOTOXIC DRUGS IN OVARIAN CANCER CELL LINES
}

\author{
Marta Nowacka ${ }^{1}$, Barbara Ginter-Matuszewska ${ }^{2}$, Monika Świerczewska ${ }^{1}$, Michał Nowicki ${ }^{1}$,
} Maciej Zabel ${ }^{3,4}$, Karolina Sterzyńska ${ }^{1}$, Radosław Januchowski ${ }^{3}$

\begin{abstract}
Resistance to chemotherapy is the main obstacle in contemporary ovarian cancer treatment. The aim of this study was the evaluation of expression of HERC5, IFIH1, SAMD4, MCTP1 and SEMA3A mRNA and assessment their role in resistance to cisplatin, paclitaxel, doxorubicin and topotecan in seven ovarian cancer cell lines. MTT assay was used in resistance assessment. Quantitative polymerase chain reaction was performed to measure the expression levels of the genes. We observed different levels of resistance among cell lines. The resistance was not related to the expression of drug transporters genes. The expression of $H E R C 5$ and IFIH1 genes was upregulated, and the expression of SEMA3A gene was downregulated. Expression of SAMD4 was upregulated in PEA1, PEA2, and PEO23 cell lines, and expression of MCTP1 was downregulated in A2780, PEA2, and PEO23 cell lines. Upregulation of HERC5, IFIH1, and SAMD4 and downregulation of SEMA3A and MCTP1 in TOP-resistant ovarian cancer cell lines may suggest some role of those genes in topotecan resistance development.
\end{abstract}

Running title: Expressions of selected genes in ovarian cancer cell lines

Keywords: ovarian cancer; cytotoxic drug resistance; new genes

\footnotetext{
${ }^{1}$ Department of Histology and Embryology, Poznań University of Medical Sciences, Poznań, Poland

${ }^{2}$ Department of Infectious Diseases, Hepatology and Acquired Immunodeficiency, Poznań University of Medical Sciences, Poland

${ }^{3}$ Department of Anatomy and Histology, Collegium Medicum, University of Zielona Góra, Zielona Góra, Poland

${ }^{4}$ Division of Histology and Embryology, Department of Human Morphology and Embryology, Wrocław Medical University, Wrocław, Poland

*Correspondence: mnowacka@ump.edu.pl

Full list of author information is available at the end of article
} 


\section{Introduction}

Epithelial ovarian cancer (EOC) is one of the most aggressive tumors and the most common cause of death from gynecological malignancies [1,2]. In most cases, the diagnosis comes in advanced disease with intraperitoneal metastasis [3]. The standard treatment includes surgery with the following chemotherapy. The first line of chemotherapy consists of the combination of platinum compounds (cisplatin - CIS or carboplatin) and taxanes (paclitaxel - PAC) [4]. Although most patients are sensitive to the first line of chemotherapy, about five percent of patients are already resistant at the beginning of treatment. Among initially sensitive patients, most will develop drug resistance and will require further therapy with other drugs [4]. However, the response to the second-line of chemotherapy is usually low because of the different existing mechanisms of drug resistance [4]. CIS is an essential drug used in ovarian cancer chemotherapy [4]. The effect of its action in the cell is an inhibition of DNA replication and RNA transcription in consequence of DNA cross-linking [5]. Different types of CIS-resistance mechanisms in cancer cells have been described so far. The most important are: drug inactivation by sulfhydryl-containing molecules like glutathione and metallothioneins, decreased drug uptake, the drug removal by transporters from the $\mathrm{ABC}$ family such as $\mathrm{ABCC} 2$ (MRP2) and the repair of damaged DNA via DNA repair systems [6]. PAC acts as mitosis blocker, what finally causes apoptotic cell death [7]. The most important mechanism of PAC resistance is related to the expression of drug transporters such as ABCB1 (glycoprotein P (P-gp) [8] and ABCB4 [8, 9]. The drugs used in the second line of ovarian cancer chemotherapy affect the replication process $[10,11]$. DOX is an inhibitor of DNA topoisomerase II, while TOP of DNA topoisomerase I. Binding of DOX or TOP to topoisomerase results in the formation of irreversible covalent cross-links between topoisomerase and DNA, resulting in cell death [12]. The most important mechanism of resistance seems to be effective removal by drug transporters. DOX is a substrate of P-gp (ABCB1) efflux pomp [13], while TOP is mainly removed by breast cancer resistant protein (BCRP, ABCG2) [14], although P-gp dependent resistance to TOP has also been described $[8,15]$. Recently we also observed increased expression of ECM molecules in DOX- [16], PAC and TOP-resistant ovarian cancer cell lines $[17,18,19]$.

We have previously proposed that the drug resistance might be a consequence of the drug transporters expression but also other pathways of drug resistance development are possible. We have recently described new genes, the expression of which alters in CIS-, PAC- and TOP- resistant ovarian cancer cell lines $[20,21,22]$. HERC5 (HECT Domain and RCC1-Like Domain-Containing Protein 5, HECT-type E3 protein ligase) is an in- terferon-induced E3 protein ligase responsible for the ISGylation of protein targets [23]. During oncogene-mediated-transformation HERC5-dependent p53 ISGylation plays a role in p53 inactivation [24]. In prostate cancer expression of HERC5 and ISGylation affects the proliferation of cells, indicating their role in malignant transformation [25]. Recently, we have observed increased expression of HERC5 gene in different TOP-resistant and sensitive EOC cell lines after first explosion to TOP [20]. IFIH1 encoded by Melanoma Differentiation-Associated gene 5 (MDA5 ) is a cytosolic receptor and plays an important role in the first line of defense against viral infection [26]. However, the ectopic expression of the IFIH1 gene can also induce the death of melanoma cells [27]. We have previously observed increased expression of the IFIH1 gene in TOP-resistant EOC cell lines developed from W1, A2780 and SKOV-3 drug-sensitive cell lines [21]. SAMD4 (Sterile Alpha Motif Domain containing $4 \mathrm{~A}$ ), also known as a SMAUG1, is a regulatory protein that regulates target mRNAs by binding to Smaug Recognition Elements (SREs) [28]. It plays a role in post-transcriptional regulation of genes expression by inhibition of translation and mRNA decay $[28,29]$. In our research, we observed increased expression of the SAMD4 gene in four TOP-resistant ovarian cancer cell lines of different origin [21]. SEMA3A is a member of the semaphorin family, which comprises eight classes where only class 3 SEMAs (SEMA3) are secreted type among vertebrates. Different members of class 3 SEMAs, including SEMA3A, have been described as anti-angiogenic agents [30]. SEMA3A is often downregulated in different types of cancer, including gastric cancer [31], tongue cancer [32], ovarian cancer [33] and thus is a putative tumor suppressor gene. In gastric and ovarian cancer, downregulation of SEMA3A expression correlated with disease progression and poor prognosis $[31,33]$. Recently we described the down-regulation of the SEMA3A gene in primary and established resistance to PAC in ovarian cancer cell lines [22]. MCTP1 (multiple transmembrane protein 1 ) is a protein with specific C2-domains in its structure [34]. The C2 domain is a Ca2+-binding motif present in proteins involved in membrane trafficking/exchange action that is valid for cell migration vesicle formation, receptor trafficking, and neurotransmitter release [35]. Different expression of MCTP1 was observed among colorectal cancer specimens [36]. In our previous reports, we described the downregulation of MCTP1 expression in CIS-, TOP- [20], and PAC-resistant [22] ovarian cancer cell lines. Drug resistance remains still a reason for chemotherapy failure in ovarian cancer. About five percent of ovarian epithelial tumors are resistant to chemotherapy at the beginning of treatment, and others develop resistance during treatment. We compared the expression of described genes in ovarian cancer cell lines isolated from untreated and treated patients. 


\section{Materials and Methods \\ Reagents}

CIS, PAC, DOX, TOP, RPMI-1640, DMEM and MEM media, fetal bovine serum, antibiotic-antimycotic solution, sodium private, insulin and L-glutamine were purchased from Sigma (St. Louis, MO, USA).

\section{Cell Lines and Cell Culture}

Cell lines used in this study are summarized in table 1. The human ovarian carcinoma A2780, SKOV-3, and OVCAR-3 were purchased from ATCC (American Type Culture Collection, Manassas, VA, USA). The human ovarian carcinoma PEA1, PEA2, and PEO23 were purchased from Sigma (St. Louis, MO, USA). W1 cell line was isolated from an untreated female patient diagnosed for serous ovarian adenocarcinoma by our team, as described previously [16]. The cells grow as a monolayer and present an epithelial morphology and adherent growth model. A2780 [37] and PEA1 [38] cell lines were also isolated from an untreated patient. PEA2 cell line was isolated from the same patients as PEA1 after ineffective treatment with CIS and Prednimustine chemotherapy [38] and PEO23 was isolated from another ovarian cancer patient after CIS and chlorambucil treatment failed [38]. SKOV-3 were isolated from patients treated with ThioTEPA therapy [37] and OVCAR-3 was isolated from malignant ascites of ovarian cancer patients after combination chemotherapy with cyclophosphamide, DOX and CIS [39]. Cells were cultured in Minimum Essential Medium Eagle (MEM) medium (A2780), RPMI-1640 medium (W1), RPMI-1640 medium supplemented with $2 \mathrm{mM}$ sodium private (PEA1, PEA2, PEO23),
RPMI-1640 medium supplemented with insulin $(0,1$ unit $/ \mathrm{mL})$ (OVCAR-3) or Dulbecco's Modified Eagle Medium (DMEM) (SKOV-3), supplemented with $20 \%$ (RPMI-1640 with insulin) or $10 \%$ fetal bovine serum (MEM, RPMI-1640, RPMI-1640 with sodium private, DMEM), $200 \mathrm{~mL}$-glutamine, penicillin (100 units/mL), streptomycin (100 units/mL), and amphotericin B $(25 \mu \mathrm{g} / \mathrm{mL})$ at $37 \mathrm{C}$ in an environment of $5 \% \mathrm{CO} 2$.

\section{Examination of Gene Expression by Q-PCR}

We examined changes in HERC5, IFIH1, SEMA3A, SAMD4 and MCTP1 gene expression in all investigated cell lines. According to the manufacturer's protocol, we isolated RNA using a Gene Matrix Universal RNA Purification Kit (EURx, Ltd., Gdańsk, Poland) and performed reverse transcription experiment using $2 \mu \mathrm{g}$ of RNA for cDNA synthesis and M-MLV reverse transcriptase kit (Invitrogen by Thermo Fisher, Waltham, MA, USA) and thermal cycler (Veriti 96-well Thermal Cycler, Applied Biosystems, 850 Lincoln Centre Drive, Foster City, CA, USA). Sequence-specific primers described in table 2 were used for Real-time PCR analysis performed using a 7900HT Fast Real-Time PCR System (Applied Biosystems, 850 Lincoln Centre Drive, Foster City, CA, USA), Maxima SYBR Green/ROX qPCR Master Mix (Thermo Fisher Scientific, Waltham, MA, USA). Following house-keeping genes were used as normalizing genes: glyceraldehyde-3-phosphate dehydrogenase (GADPH), $\beta$-actin, hypoxanthine-guanine phosphoribosyltransferase 1 (HRPT1) and beta-2-microglobulin $(\beta 2 \mathrm{M})$. The $\mathrm{W} 1$ cell lines were used as the calibrator for the relative quantification (RQ) method

TABLE 1 Characterization of cell lines used in this study

\begin{tabular}{|c|c|c|c|}
\hline Cell line & Origin & Chemotherapy & $\begin{array}{c}\text { Treatment } \\
\text { outcome }\end{array}$ \\
\hline W1 & $\begin{array}{c}\text { tumor tissue, ovarian serous } \\
\text { adenocarcinoma }\end{array}$ & No & $\mathrm{N} / \mathrm{A}$ \\
\hline A2780 & $\begin{array}{l}\text { tumour tissue, ovarian endometrioid } \\
\text { adenocarcinoma }\end{array}$ & No & $\mathrm{N} / \mathrm{A}$ \\
\hline SKOV-3 & ascites, ovarian serous adenocarcinoma & ThioTEPA & ineffective \\
\hline OVCAR-3 & $\begin{array}{l}\text { ascites, ovarian serous adenocarcinoma, } \\
\text { high grade }\end{array}$ & $\begin{array}{l}\text { cyclophosphamide, } \\
\text { DOX, CIS }\end{array}$ & ineffective \\
\hline PEA1 & $\begin{array}{c}\text { pleural effusion, serous adenocarcinoma, } \\
\text { high grade }\end{array}$ & No & $\mathrm{N} / \mathrm{A}$ \\
\hline PEA2 & $\begin{array}{l}\text { ascites, serous adenocarcinoma, high } \\
\text { grade }\end{array}$ & CIS, Prednimustine & ineffective \\
\hline PEA 023 & $\begin{array}{l}\text { ascites, serous adenocarcinoma, } \\
\text { low grade }\end{array}$ & CIS, chlorambucil & ineffective \\
\hline
\end{tabular}


of gene expression analysis. The standard formula was employed: RQ = [sample (investigated cell line) calibrator (W1 cell line). The graphs were made using SigmaPlot (Systat Software GmbH Schimmelbuschstrasse 25 D-40699, Erkrath, Germany).

The amplification was processed with the use of: 12.5 $\mu \mathrm{L}$ of Maxima SYBR Green/ROX qPCR Master Mix (Fermentas by Thermo Fisher, Waltham, MA, USA), $1 \mu \mathrm{L}$ of each primer (Oligo, Warsaw, Poland, Tab. 2), $9.5 \mu \mathrm{L}$ of water, and $1 \mu \mathrm{L}$ of cDNA solution. For each experiment as a negative control one RNA sample was processed without the RT-reaction. The process of amplification included a hot start (95 ${ }^{\circ} \mathrm{C}$, $15 \mathrm{~min}$ ), 45 cycles of denaturation (95 ${ }^{\circ} \mathrm{C}$ for $15 \mathrm{~s}$ ), annealing (60 $\circ \mathrm{C}$ for $30 \mathrm{~s})$, and extension (72 $\circ \mathrm{C}$ for 30s). After amplification, melting curve analysis was performed and products of amplification were resolved by $3 \%$ agarose gel electrophoresis and visualized by ethidium bromide staining.

\section{Drug sensitivity assay}

The drug sensitivity/resistance of the investigated cell lines was determined by an MTT cell survival assay. 4,000 cells of each cell line were seeded in each well of 96-well plates. After $48 \mathrm{~h}$ of culturing, cells were treated with fresh medium supplemented with or without increasing concentrations of CIS, PAC, DOX or TOP. After $72 \mathrm{~h}$ incubation at $37^{\circ} \mathrm{C}$, the medium was supplemented with $10 \mu \mathrm{l}$ of the MTT labeling reagent (the final concentration of MTT was $0.5 \mathrm{mg} / \mathrm{ml}$ ), and the cells were incubated for an additional $4 \mathrm{~h}$. After this time, to each well, a 100 $\mu$ of solubilization solution was added. The absorbance was measured using a microplate reader at $570 \mathrm{~nm}$ with a reference wavelength of $720 \mathrm{~nm}$, according to the manufacturer's protocol. As a negative control, a cell-free culture medium containing both the MTT reagent and solubilization solution was used. Each experiment was repeated three times, and each concentration in a given experiment was tested in duplicates. IC50 value of each drug in each cell line was determined. Cell resistance/sensitivity was expressed as the fold of that in the W1 cell line, which was assigned as a 1.

\section{Statistical Analysis}

Data are presented as the standard error of the mean (SEM) and were analyzed using Student's t-test. $\mathrm{p}<0.05$ was considered to indicate a statistically significant difference.

\section{Results}

MTT analysis of response to the cytotoxic drug in investigated cell lines

At the beginning of our investigation, we were interested if there are any differences in response to the drugs used in ovarian cancer chemotherapy between different ovarian cancer cell lines. In our study following ovarian cancer cell lines were examined: high-grade serous-OVCAR3, PEA1, PEA2; low-grade serous-PEO23; serous-SKOV-3; endometrioid adenocarcinoma - A2780 [37] and primary

TABLE 2 Oligonucleotide sequences used for Q-PCR analysis

\begin{tabular}{|c|c|c|c|c|}
\hline Transcript & & quence (5'-3' direction) & ENST number & $\begin{array}{c}\text { Product } \\
\text { size }\end{array}$ \\
\hline \multirow{2}{*}{ MCTP1 } & $\mathrm{F}$ & AGAACCTCAACCCTGTGTGG & \multirow{2}{*}{00000312216} & \multirow{2}{*}{$123 \mathrm{bp}$} \\
\hline & $\mathrm{R}$ & AGGCTGAGCCCATAAAGTCA & & \\
\hline \multirow{2}{*}{ IFIH1 } & $\mathrm{F}$ & GGGGCATGGAGAATAACTCA & \multirow{2}{*}{00000263642} & \multirow{2}{*}{$132 \mathrm{bp}$} \\
\hline & $\mathrm{R}$ & TGCCCATGTTGCTGTTATGT & & \\
\hline \multirow{2}{*}{ SAMD4 } & $\mathrm{F}$ & CCAAAGGTGCAAGACACAAA & \multirow{2}{*}{00000251091} & \multirow{2}{*}{$146 \mathrm{bp}$} \\
\hline & $\mathrm{R}$ & CGGAGTCAGGATCATCTGGT & & \\
\hline \multirow{2}{*}{ HERC5 } & $\mathrm{F}$ & CTTCCTGCATGTGGTTTCCT & \multirow{2}{*}{00000264350} & \multirow{2}{*}{$128 \mathrm{bp}$} \\
\hline & $\mathrm{R}$ & AAACAGTGCCAGTGGGAAAG & & \\
\hline \multirow{2}{*}{ SEMA3A } & $\mathrm{F}$ & TGTTGGAGCAAAGGATCACA & \multirow{2}{*}{00000265362} & \multirow{2}{*}{$109 \mathrm{bp}$} \\
\hline & $\mathrm{R}$ & AGCCCACTTGCATTCATCTC & & \\
\hline \multirow{2}{*}{ GAPDH } & $\mathrm{F}$ & GAAGGTGAAGGTCGGAGTCA & \multirow{2}{*}{00000229239} & \multirow{2}{*}{$199 \mathrm{bp}$} \\
\hline & $\mathrm{R}$ & GACAAGCTTCCCGTTCTCAG & & \\
\hline \multirow{2}{*}{$\beta$-actin } & $\mathrm{F}$ & TCTGGCACCACACСТTCTAC & \multirow{2}{*}{00000331789} & \multirow{2}{*}{$169 \mathrm{bp}$} \\
\hline & $\mathrm{R}$ & GATAGCACAGCCTGGATAGC & & \\
\hline \multirow{2}{*}{ HPRT1 } & $\mathrm{F}$ & CTGAGGATTTGGAAAGGGTG & \multirow{2}{*}{00000298556} & \multirow{2}{*}{$156 \mathrm{bp}$} \\
\hline & $\mathrm{R}$ & AATCCAGCAGGTCAGCAAAG & & \\
\hline \multirow{2}{*}{$\mathrm{B} 2 \mathrm{M}$} & $\mathrm{F}$ & CGCTACTCTCTCTTTCTGGC & \multirow{2}{*}{00000558401} & \multirow{2}{*}{$133 \mathrm{bp}$} \\
\hline & $\mathrm{R}$ & ATGTCGGATGGATGAAACCC & & \\
\hline
\end{tabular}


ovarian cancer cell line-W1 [16]. W1 cell line was isolated from the untreated patient by our team, as described previously [16]. A2780 [37] and PEA1 [38] cell lines were also isolated from an untreated patient. The PEA2 cell line was isolated from the same patient as PEA1 after ineffective treatment with CIS and Prednimustine chemotherapy [38], and PEO23 was isolated from another ovarian cancer patient after CIS, and chlorambucil treatment failed [38]. SKOV-3 was isolated from patient treated with ThioTEPA therapy [37], and OVCAR-3 was isolated from malignant ascites of ovarian cancer patient after combination chemotherapy with cyclophosphamide, DOX, and CIS [39].

In order to determine the drug sensitivity, cells were treated with increasing concentration of CIS, PAC, DOX, or TOP. We used a W1 cell line as a refer- ence because this cell line was sensitive to cytotoxic drugs used in ovarian cancer therapy, as we determined previously [15]. Thus, the level of resistance in this cell line was assigned as one. We defined difference in resistance as a low - increase/decrease up to 10 -fold, medium - between 10 and 20-fold, high - between 20 and 50-fold and very high - over 50 -fold. In all cell lines, we observed a statistically significant increase in IC50 value for CIS with a low increase in A2780 and SKOV-3 cell lines and an average increase in OVCAR-3, PEA1, PEA2 and PE023 cell lines (Tab. 3). In the case of PAC resistance, we did not observe statistically significant differences between W1 and A2780, as well as W1 and PEA1 cell lines. The low increase we observed in PEA2 cell line, and a very high increase in resistance was observed in OVCAR-3 and PEO23 cell lines. In

TABLE 3 Summary of cell lines resistance to cisplatin, paclitaxel, doxorubicin and topotecan treatment

\begin{tabular}{|c|c|c|c|c|}
\hline \multirow[t]{2}{*}{ Cell line } & \multicolumn{4}{|c|}{ IC50 (ng/ml) } \\
\hline & cisplatin & paclitaxel & doxorubicin & topotecan \\
\hline W1 & $\begin{array}{c}151 \\
(96-216) \\
\underline{1}\end{array}$ & $\begin{array}{c}3,37 \\
(3,18-3,62) \\
\underline{1}\end{array}$ & $\begin{array}{c}13,6 \\
(9,1-18,0) \\
\underline{1}\end{array}$ & $\begin{array}{c}2,03 \\
(1,94-2,11) \\
\underline{1}\end{array}$ \\
\hline A2780 & $\begin{array}{c}439 \\
(283-565) \\
\underline{2,9 \uparrow^{*}}\end{array}$ & $\begin{array}{c}3,43 \\
(1,91-4,73) \\
\underline{1,02 \uparrow}\end{array}$ & $\begin{array}{c}19,79 \\
(12,52-24,44) \\
\underline{1,46 \uparrow}\end{array}$ & $\begin{array}{c}3,13 \\
(1,48-4,71) \\
\underline{1,54 \uparrow}\end{array}$ \\
\hline SKOV-3 & $\begin{array}{c}890 \\
(595-1222) \\
\underline{5,8 \uparrow * *}\end{array}$ & $\begin{array}{c}0,784 \\
(0,73-0,84) \\
\underline{4,30 \downarrow^{* *}}\end{array}$ & $\begin{array}{c}17,76 \\
(13,7-22,84) \\
\underline{1,31 \uparrow}\end{array}$ & $\begin{array}{c}51,9 \\
(40,34-60,71) \\
\underline{25,6 \uparrow * * *} \\
\end{array}$ \\
\hline OVCAR-3 & $\begin{array}{c}2613 \\
(2125-2884) \\
\underline{17,3 \uparrow * * *} \\
\end{array}$ & $\begin{array}{c}458 \\
(372-594) \\
136 \uparrow * * * \\
\end{array}$ & $\begin{array}{c}354 \\
(203-571) \\
\underline{26 \uparrow * *}\end{array}$ & $\begin{array}{c}398 \\
(283-505) \\
\underline{196 \uparrow * * *}\end{array}$ \\
\hline PEA1 & $\begin{array}{c}2737 \\
(2031-3763) \\
\underline{18,1 \uparrow * *}\end{array}$ & $\begin{array}{c}5,66 \\
(3,25-9,07) \\
\underline{1,68 \uparrow}\end{array}$ & $\begin{array}{c}81 \\
(72-90) \\
5,96 \uparrow * * \\
\end{array}$ & $\begin{array}{c}29 \\
(19,2-46,9) \\
\underline{14,3 \uparrow * *}\end{array}$ \\
\hline PEA2 & $\begin{array}{c}2469 \\
(2426-2557) \\
16,4 \uparrow * * * \\
\end{array}$ & $\begin{array}{c}6,88 \\
(4,31-8,38) \\
\underline{2,04 \uparrow *}\end{array}$ & $\begin{array}{c}173 \\
(148-195) \\
12,7 \uparrow * * \\
\end{array}$ & $\begin{array}{c}132 \\
(79-188) \\
\underline{65 \uparrow * *} \\
\end{array}$ \\
\hline PE023 & $\begin{array}{c}2171 \\
(1839-2438) \\
14,4 \uparrow * * * \\
\end{array}$ & $\begin{array}{c}1404 \\
(1000-1600) \\
417 \uparrow * * * \\
\end{array}$ & $\begin{array}{c}275 \\
(198-375) \\
\underline{20,2 \uparrow * * *} \\
\end{array}$ & $\begin{array}{c}498 \\
(300-750) \\
\underline{245 \uparrow * *}\end{array}$ \\
\hline
\end{tabular}

IC50 mean is indicated to cisplatin, paclitaxel, doxorubicin and topotecan. The drug resistance in the W1 cell line was assigned as 1 . Underline values indicate multiplicities of resistance with respect to the $\mathrm{W} 1$ cell line.

$$
{ }^{*} \mathrm{p}<0.05,{ }^{* *} \mathrm{p}<0.01,{ }^{* * *} \mathrm{p}<0.001
$$


contrast, SKOV-3 cell line was over 4,30-fold more sensitive to PAC in comparison to the W1 cell line (Tab. 3). Next, we were interested in drugs from the second line of ovarian cancer chemotherapy. Similar sensitivity to DOX was observed in W1, A2780 and SKOV-3 cell lines. In the PEA1 cell line, we observed a low increase in resistance and in PEA2, we observed an average increase in DOX resistance. A high increase in DOX resistance was observed in OVCAR-3 and PE023 cell lines (Tab. 3). We observed similar sensitivity to TOP in W1 and A2780 cell lines. An average increase was observed in PEA1 cell line, whereas SKOV-3 showed a high increase in TOP resistance. The highest increase was observed in PEA2, PEO23, and OVCAR-3 cell lines (Tab. 3).

\section{Gene expression analysis in ovarian cancer cell lines}

Previously we observed increased expression of HERC5 [20], SAMD4, and IFIH1 [21] in TOP-resistant ovarian cancer cell lines. Decreased expression of MCTP1 in CIS-, TOP- [20], and PAC-resistant [22] cell lines and decreased expression of SEMA3A in PAC-resistant cell lines [22]. Since we observed increased resistance to these drugs in investigated cell lines, we were interested if it reflects by changes in gene expression. Thus, we examined the genes expression level of HERC5, SAMD4, IFIH1, MCTP1, and SEMA3A. We observed a statistically significant increase of HERC5 gene in all investigated cell lines in comparison to W1 cell line with the low increase in A2780 and PEO23 ( $p<0.05)$ as well as OVCAR-3 and PEA2 $(p<0.01)$ cell lines and medium increase in SKOV3 $(p<0.001)$ and PEA1 $(p<0.01)$ cell lines (Fig. 1A).

Similarly, we observed a statistically significant increase of IFIH1 gene expression in all investigated cell lines with the low increase in A2780 cell line $(p<0.05)$, the medium increase in SKOV3 and OVCAR- 3 cell lines $(p<0.05)$, the high increase in PEA1 and PEO23 cell lines ( $p<0.01)$, and very high increase $(153$-fold) in PEA2 cell line $(p<0.05)$ (Fig.
1B).The expression of the SAMD4 gene was slightly downregulated in the A2780 cell line ( $<<0.05)$ and slightly upregulated in the PE023 cell line ( $\mathrm{p}<$ 0.05). Clear increase in SAMD4 expression was observed in PEA1 and PEA2 cell lines ( $p<0.05$ and $\mathrm{p}<0.01$, respectively), (Fig. 1C). The expression of SEMA3A and MCTP1 was downregulated in investigated cell lines when compared to the W1 cell line. In all investigated cell lines, we observed statistically significant decrease in expression of SEMA3A gene, with low decrease in A2780, SKOV-3, PEA2 $(\mathrm{p}<0.05)$ and PE023 $(\mathrm{p}<0.01)$ cell lines, medium decrease in OVCAR-3 cell line $(p<0.001)$ and high decrease in PEA1 cell line $(\mathrm{p}<0.01)$ (Fig. 2A). Expression of MCTP1 gene was downregulated at medium level in A2780 ( $p<0.05)$ and PEO23 ( $<<0.01)$ cell line. High downregulation of MCTP1 gene was observed in PEA2 $(\mathrm{p}<0.05)$ cell line (Fig. 2B).

\section{Discussion}

Since drug resistance is a significant obstacle in the effective treatment of cancer, research on this phenomenon is still necessary. As some of the ovarian cancer patients are initially resistant at the beginning of the therapy and some of them acquire resistance during treatment, the drug resistance phenomenon seems to be complex and many molecular factors contributing to drug resistance still remain unrevealed.

Most of the investigations use a model of drug sensitive-resistant pairs of cell lines and concentrate on acquired drug resistance. Much less is known about primary resistance to cytotoxic drugs. Previously we described the increased expression of a set of new genes in drug-resistant cell lines developed from drug-sensitive ovarian cancer cell lines [20,21, 22]. Here we investigate whether these genes are involved in primary or developed in vivo drug resistance in EOC. In this study, we used different ovarian cancer cell lines isolated from patients before or after chemotherapy treatment [16,37-39].
A
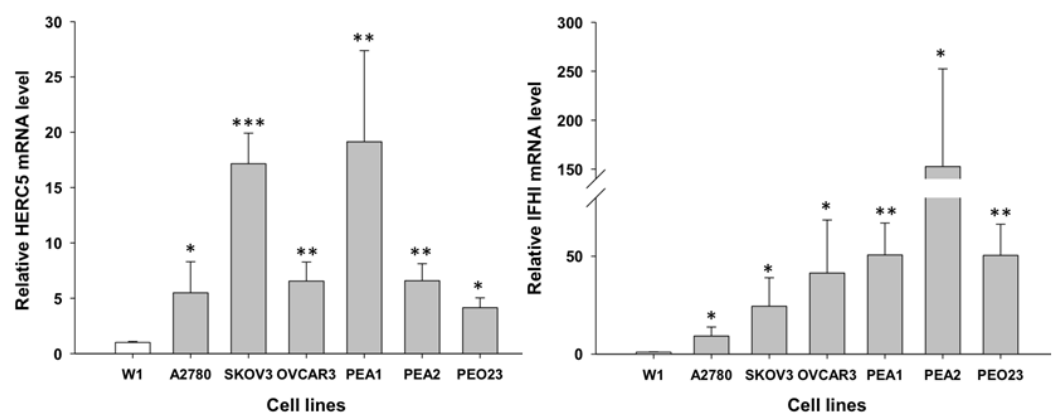

Cell lines
C

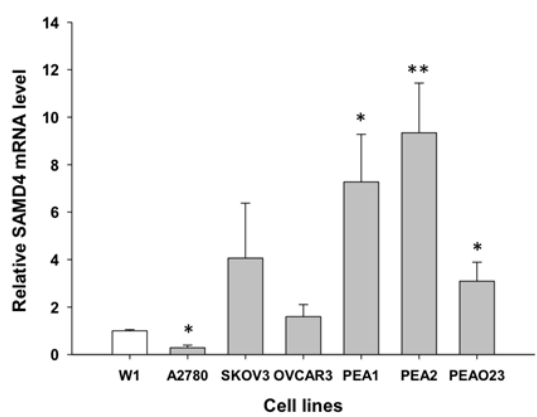

FIGURE 1 Expression analysis (Q-PCR) of the HERC5 (A), IFIH1 (B), and SAMD4 (C) transcripts in different ovarian cancer cell lines. The figure presents the relative gene expression in cell lines (grey bars) with respect to the W1 cell line (white bar), which was assigned a value of 1 . The values were considered significant at ${ }^{*} \mathrm{p}<0.05,{ }^{* *} \mathrm{p}<0.0$ and ${ }^{* * *} \mathrm{p}<0.001$ 
A

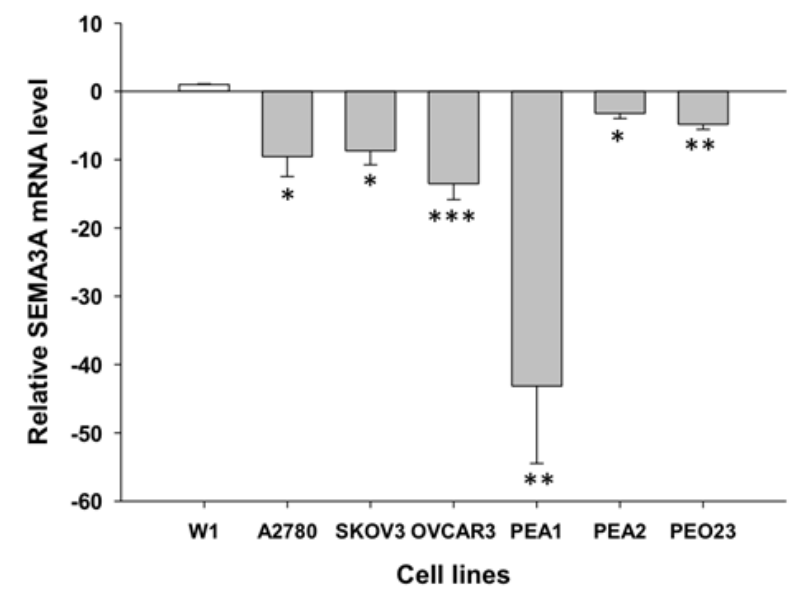

B

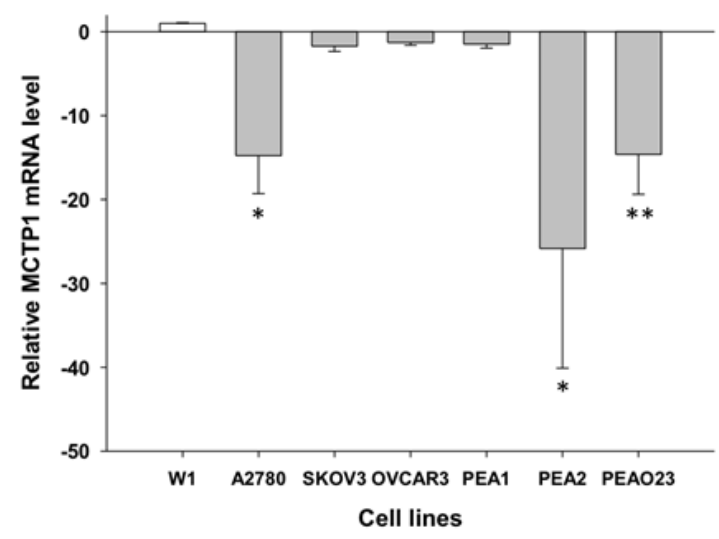

FIGURE 2 Expression analysis (Q-PCR) of the SEMA3A (A) and MCTP1 (B) transcripts in different ovarian cancer cell lines. The figure presents the relative gene expression in cell lines (grey bars) with respect to the W1 cell line (white bar), which was assigned a value of 1 . The values were considered significant at $* \mathrm{p}<0.05,{ }^{* *} \mathrm{p}<0.01$ and ${ }^{* * *} \mathrm{p}<0.001$

As a baseline cell line, we used W1 cell line that was sensitive to all drugs used in ovarian cancer chemotherapy, as we described previously [15]. The results of chemoresistance experiments conducted on all investigated cell lines revealed differences in response to drugs used in the first and second line of chemotherapy. The expressions of genes encoding drug transporters like $M D R 1, M D R 3$ or $M R P 2$ were low in $\mathrm{W} 1$ and even lower in other cell lines (not shown), thus drug resistance in investigated cell lines seems not to be related to the expression of drug transporters. Therefore, we focused on other genes that we previously described in the context of drug resistance development in EOC cell lines.

We observed increased expression of HERC5, IFIH1 and SAMD4 genes. The upregulation of the HERC5 gene was noted for all cell lines that were simultaneously more resistant to TOP than the W1 cell line. It remains in line with our previous observation where increased expression of HERC5 gene was described in TOP-resistant cell lines derived from W1 and A2780 cell lines. Furthermore, short-time treatment of W1 and A2780 cell lines with a low dose of TOP also leads to increased expression of HERC5 gene [20]. HERC5 is part of the ING15 protein degradation system with low activity in healthy tissue $[23,24]$. In contrast, high activity of this system was observed in the prostate [40], pancreatic [41], breast [42] and bladder [43] tumors suggesting its role in cancer progression. The expression of HERC5 was upregulated in hepatocellular carcinoma tissues and cell lines, and knock-down of HERC5 resulted in increased apoptosis [44]. HERC5 has also been identified as a risk factor in breast cancer and correlated with tumor stage, grade and lymph node metastases [45]. Summarizing all these results, one can hypothesize about a particular role of increased expression of HERC5 in drug resistance and progression of different cancers.
The expressions of IFIH1 and SAMD4 have not been particularly described in the context of drug resistance so far. IFIH1 gene plays a role in first-line defense against viral infections [26]. In terms of tumor progression, the downregulation of this gene was observed in prostate cancer and cell lines resistant to docetaxel [46]. IFIH1 was also identified as one of the essential genes in cancer resistance to radiotherapy [47]. Previously, we observed increased expression of the IFIH1 gene in five TOP-resistant cell lines derived from W1, A2780 and SKOV-3 cell lines as well as in primary response to short-time treatment in A2780 and SKOV-3 cell lines [21]. These results may indicate some role of this gene in TOP resistance. Here, we also observed increased expression of IFIH1 in all cell lines resistant to TOP. Furthermore, IFIH1 expression increased in PEA2 when compared to PEA1, along with increased TOP and DOX resistance between these cell lines. It supports the significance of IFHI1 gene expression not only in TOP but possibly also in DOX resistance.

Finally, the last gene observed to be upregulated in PEA1, PEA2, and PE023 cell lines was SAMD4 (SMAUG1). As these cell lines were more resistant to CIS, DOX, and TOP, the probable relation between elevated levels of this protein and drug resistance may be assumed. However, the role of SAMD4 in drug resistance or even in cancer progression was not described so far by others. The results obtained previously revealed increased expression of the SAMD4 gene in four from five TOP-resistant cell lines derived from W1, A2780, and SKOV-3 cell lines. Furthermore, we observed its increased expression after short-time exposure to TOP in A2780 and SKOV-3 cell lines [21]. Based on these observations, some role of the $S A M D 4$ gene expression in TOP-resistance may be assumed. However, more detailed studies are required to resolve this issue. 
It seems much more complicated to determine the role of two successive genes which expression in the examined cell lines was decreased when compared to the W1 cell line. Previously, we have reported downregulation of SEMA3A gene in three from four PAC-resistant cell lines as well as in shorttime response to PAC treatment in A2780 cell line [22]. Here, we observed downregulation of the $S E$ $M A 3 A$ gene in all cell lines, although only OVCAR-3 and PE023 were simultaneously much more resistant to PAC. However, all cell lines were more resistant to CIS, and more substantial downregulation of SEMA3A gene was observed in OVCAR-3 and PEA1 cell lines that were more resistant to CIS. The literature data show no relationship between SEMA3A downregulation and drug resistance. However, such downregulation was observed in cancers where it correlated with disease progression. In gastric tumor decreased SEMA3A expression was associated with poor differentiation, depth of invasion, number of lymph node and distant metastases, advanced TNM stage and poor patient's prognosis [31]. Lower expression of SEMA3A was also observed in EOC in comparison to the normal epithelium and correlated with poor histological grade, higher clinical advancement (FIGO), lymph node and distant metastases and poor prognosis [33]. Similarly, for tongue cancer, decreased SEMA3A expression correlated with nodal metastasis and predicted shorter patient's survival [32]. All cases described above indicate that the downregulation of SEM $3 A$ was mainly observed in metastases. One of the features of metastases is that they are usually more resistant to chemotherapy than primary tumors. However, it cannot be said that SEMA3A is directly involved in drug resistance because this gene is downregulated in resistant cell lines. Instead, the loss of its function may lead to the activation of some molecular events leading to drug resistance. It has been reported that reduced SEMA3A expression can result in higher protein phosphorylation and enhanced signal transduction [48]. Higher levels of protein phosphorylation are one of the characteristics of drug-resistant cells [49] that we have also observed in drug-resistant ovarian cancer cell lines previously [50].

The MCTP1 gene has not been described in the context of drug resistance by others so far. It is poorly described in the literature. Among cancers, its expression was only investigated in colorectal cancer but did not correlate with any clinical data [36]. Here, we observed decreased expression of the MCTP1 gene only in A2780, PEA2, and PE023 cell lines. All these cell lines are more resistant to TOP, DOX, and CIS than the W1 cell line that suggests its putative, unknown so far, role in resistance to these drugs. Significantly lower expression of MCTP1 was observed for PEA1 cell line when compared to PEA2, where PEA2 is more resistant to DOX and TOP as well. Since PEA2 was derived from the same patient as the PEA1 cell line but after chemotherapy [38], it is possible that as in our in vitro study [20, 21, 22], the downregulation of MCTP1 may be a non-specific response of cancer cells to contact with cytotoxic drugs. Like SEMA3A, the MCTP1 is probably not directly related to drug resistance, but the loss of its function may lead to the activation of some molecular processes that increase resistance. Thus, determining the role of MCTP1 in cancer progression and drug resistance requires further investigation.

\section{Conclusions}

In summary, we described five new genes that may play a role in resistance to cytotoxic drugs used in EOC chemotherapy. However, we are aware that at this point, our results have some limitations. Revealing the expression pattern of new genes associated with the drug resistance phenomenon provides a preliminary insight into its role as a potential therapeutic agent. The exact role of these genes in drug resistance requires further investigation.

\section{Ethical approval}

The conducted research is not related to either human or animal use.

\section{Acknowledgement}

This study was supported by Grant No. 2014/13/B/NZ5/00334 from the National Science Centre, Kraków, Poland.

\section{Corresponding author}

Marta Nowacka, Department of Histology and Embryology, Poznan University of Medical Sciences, PL-61-781, Tel.: +48-618546455, e-mail: mnowacka@ump.edu.pl.

\section{Conflicts of interest}

The authors declare they have no conflict of interest.

\section{References}

1. Siegel RL, Miller KD, Jemal A. Cancer statistics, 2019. CA Cancer J Clin 2019;69(1):7-34; DOI:10.3322/caac.21551.

2. Webb PM, Jordan SJ. Epidemiology of epithelial ovarian cancer Best Pract Res Clin Obstet Gynaecol. 2017;41:3-14; DOI:10.1016/j. bpobgyn.2016.08.006.

3. Pignata S, C Cecere S, Du Bois A, Harter P, Heitz F. Treatment of recurrent ovarian cancer. Annals of Oncology. 2017;28:viii51-6; DOI:10.1093/ annonc/mdx441.

4. Webber K, Friedlander M. Chemotherapy for epithelial ovarian, fallopian tube and primary peritoneal cancer. Best Pract Res Clin Obstet Gynaecol. 2017;41:126-138; DOI:10.1016/j.bpobgyn.2016.11.004

5. Kartalou M, Essigmann JM. Mechanisms of resistance to cisplatin. Mutat Res. 2001;478(1-2):23-43; DOI:10.1016/s0027-5107(01)00141-5.

6. Stewart DJ. Mechanisms of resistance to cisplatin and carboplatin. Crit Rev Oncol Hematol. 2007;63(1):12-31; DOI:10.1016/j. critrevonc.2007.02.001.

7. Jordan A, Hadfield JA, Lawrence NJ, McGown AT. Tubulin as a target for anticancer drugs: agents which interact with the mitotic spindle. Med Res Rev. 1998;18(4):259-96; DOI:10.1002/ (sici)1098-1128(199807)18:4<259::aid-med3>3.0.co;2-u.

8. Januchowski R, Sterzyńska K, Zaorska K, Sosińska P, Klejewski A, Brązert M, Nowicki M, Zabel M. Analysis of MDR genes expression and cross-resistance in eight drug resistant ovarian cancer cell lines. J Ovarian Res. 2016;9(1):65; DOI:10.1186/s13048-016-0278-z.

9. Januchowski R, Wojtowicz K, Andrzejewska M, Zabel M. Expression of MDR1 and MDR3 gene products in paclitaxel-, doxorubicin- and vincristine-resistant cell lines. Biomed Pharmacother. 2014;68(1):111-7; DOI:10.1016/j.biopha.2013.09.004.

10. Ferrandina G, Ludovisi M, Lorusso D, Pignata S, Breda E, Savarese A, Del Medico P, Scaltriti L, Katsaros D, Priolo D, Scambia G. Phase III trial of 
gemcitabine compared with pegylated liposomal doxorubicin in progressive or recurrent ovarian cancer. J Clin Oncol. 2008;26(6):890-6 DOI:10.1200/JC0.2007.13.6606.

11. Sehouli J, Stengel D, Oskay-Oezcelik G, Zeimet AG, Sommer H, Klare P, Stauch M, Paulenz A, Camara O, Keil E, Lichtenegger W. Nonplatinum topotecan combinations versus topotecan alone for recurrent ovarian cancer: results of a phase III study of the North-Eastern German Society of Gynecological Oncology Ovarian Cancer Study Group. J Clin Oncol. 2008;26(19):3176-82; DOI:10.1200/JC0.2007.15.1258.

12. Staker BL, Hjerrild K, Feese MD, Behnke CA, Burgin AB Jr, Stewart L. The mechanism of topoisomerase I poisoning by a camptothecin analog. Proc Natl Acad Sci U S A. 2002;99(24):15387-92; D0I:10.1073/ pnas.242259599.

13. Abolhoda A, Wilson AE, Ross H, Danenberg PV, Burt M, Scotto KW. Rapid activation of MDR1 gene expression in human metastatic sarcoma after in vivo exposure to doxorubicin. Clin Cancer Res. 1999;5(11):3352-6.

14. Robey RW, Polgar O, Deeken J, To KW, Bates SE. ABCG2: determining its relevance in clinical drug resistance. Cancer Metastasis Rev. 2007;26(1):39-57; DOI:10.1007/s10555-007-9042-6.

15. Januchowski R, Wojtowicz K, Sujka-Kordowska P, Andrzejewska M,Zabe M. MDR gene expression analysis of six drug-resistant ovarian cancer cel lines. Biomed Res Int. 2013;2013:241763; DOI:10.1155/2013/241763.

16. Sterzyńska K, Kaźmierczak D, Klejewski A, Świerczewska M, Wojtowicz K, Nowacka M, Brazert J, Nowicki M, Januchowski R. Expression of Osteoblast-Specific Factor 2 (OSF-2, Periostin) Is Associated with Drug Resistance in Ovarian Cancer Cell Lines. Int J Mol Sci. 2019;20(16):3927, DOI:10.3390/ijms20163927.

17. Sterzyńska K, Klejewski A, Wojtowicz K, Świerczewska M, Nowacka M, Kaźmierczak D, Andrzejewska M, Rusek D, Brązert M, Brązert J, Nowicki M, Januchowski R. Mutual Expression of ALDH1A1, LOX, and Collagens in Ovarian Cancer Cell Lines as Combined CSCs- and ECM-Related Models of Drug Resistance Development. Int J Mol Sci. 2018;20(1):54 DOI:10.3390/ijms20010054

18. Klejewski A, Sterzyńska K, Wojtowicz K, Świerczewska M, Partyka M, Brązert M, Nowicki M, Zabel M, Januchowski R. The significance of lumican expression in ovarian cancer drug-resistant cell lines. Oncotarget 2017;8(43):74466-74478; DOI:10.18632/oncotarget.20169.

19. Sterzyńska K, Klejewski A, Wojtowicz K, Świerczewska M, Andrzejewska M, Rusek D, Sobkowski M, Kędzia W, Brązert J, Nowicki M Januchowski R. The Role of Matrix Gla Protein (MGP) Expression in Paclitaxel and Topotecan Resistant Ovarian Cancer Cell Lines. Int J Mol Sci. 2018;19(10):2901; DOI:10.3390/ijms19102901.

20. Świerczewska M, Klejewski A, Wojtowicz K, Brązert M, Iżycki D, Nowicki M, Zabel M, Januchowski R. New and Old Genes Associated with Primary and Established Responses to Cisplatin and Topotecan Treatment in Ovarian Cancer Cell Lines. Molecules. 2017;22(10):1717; DOI:10.3390/ molecules22101717.

21. Klejewski A, Świerczewska M, Zaorska K, Brązert M, Nowicki M, Zabel M, Januchowski R. New and Old Genes Associated with Topotecan Resistance Development in Ovarian Cancer Cell Lines. Anticancer Res. 2017;37(4):1625-1636; DOI:10.21873/anticanres.11493.

22. Świerczewska M, Klejewski A, Brązert M, Kaźmierczak D, Iżycki D, Nowicki M, Zabel M, Januchowski R. New and Old Genes Associated with Primary and Established Responses to Paclitaxel Treatment in Ovarian Cancer Cell Lines. Molecules. 2018;23(4):891; DOI:10.3390/ molecules23040891.

23. Wong JJ, Pung YF, Sze NS, Chin KC. HERC5 is an IFN-induced HECT-type E3 protein ligase that mediates type I IFN-induced ISGylation of protein targets. Proc Natl Acad Sci U S A. 2006;103(28):10735-40 DOI:10.1073/pnas.0600397103.

24. Huang YF, Bulavin DV. Oncogene-mediated regulation of p53 ISGylation and functions. Oncotarget. 2014;5(14):5808-18; DOI:10.18632/ oncotarget.2199.

25. Kiessling A, Hogrefe C, Erb S, Bobach C, Fuessel S, Wessjohann L, Seliger B. Expression, regulation and function of the ISGylation system in prostate cancer. Oncogene. 2009;28(28):2606-20; DOI:10.1038/ onc.2009.115.

26. Kato H, Takeuchi O, Sato S, Yoneyama M, Yamamoto M, Matsui K, Uematsu S, Jung A, Kawai T, Ishii KJ, Yamaguchi O, Otsu K, Tsujimura T, Koh CS, Reis e Sousa C, Matsuura Y, Fujita T, Akira S. Differential roles of MDA5 and RIG-I helicases in the recognition of RNA viruses. Nature. 2006;441(7089):101-5; DOI:10.1038/nature04734.

27. Lin L, Su Z, Lebedeva IV, Gupta P, Boukerche H, Rai T, Barber GN, Dent P, Sarkar D, Fisher PB. Activation of Ras/Raf protects cells from melanoma differentiation-associated gene-5-induced apoptosis. Cell Death Differ. 2006;13(11):1982-93; DOI:10.1038/sj.cdd.4401899.
28. Pinder BD, Smibert CA. Smaug: an unexpected journey into the mechanisms of post-transcriptional regulation. Fly (Austin). 2013;7(3):142-5; DOI:10.4161/fly.24336.

29. Aviv T, Lin Z, Lau S, Rendl LM, Sicheri F, Smibert CA. The RNA-binding SAM domain of Smaug defines a new family of post-transcriptional regulators. Nat Struct Biol. 2003;10(8):614-21; DOI:10.1038/nsb956.

30. Maione F, Molla F, Meda C, Latini R, Zentilin L, Giacca M, Seano G, Serini G, Bussolino F, Giraudo E. Semaphorin 3A is an endogenous angiogenesis inhibitor that blocks tumor growth and normalizes tumor vasculature in transgenic mouse models. J Clin Invest. 2009;119(11):3356-72; DOI:10.1172/JCI36308.

31. Tang C, Gao X, Liu H, Jiang T, Zhai X. Decreased expression of SEMA3A is associated with poor prognosis in gastric carcinoma. Int J Clin Exp Pathol. 2014;7(8):4782-94.

32. Song X, Zhang W, Zhang Y, Zhang H, Fu Z, Ye J, Liu L, Song X, Wu Y. Expression of semaphorin $3 \mathrm{~A}$ and neuropilin 1 with clinicopathological features and survival in human tongue cancer. Med Oral Patol Oral Cir Bucal. 2012;17(6):e962-8; DOI:10.4317/medoral.18168.

33. Jiang H, Qi L, Wang F, Sun Z, Huang Z, Xi O. Decreased semaphorin $3 A$ expression is associated with a poor prognosis in patients with epithelial ovarian carcinoma. Int J Mol Med. 2015;35(5):1374-80; DOI:10.3892/ ijmm.2015.2142.

34. Shin OH, Han W, Wang Y, Südhof TC. Evolutionarily conserved multiple C2 domain proteins with two transmembrane regions (MCTPs) and unusual Ca2+ binding properties. J Biol Chem. 2005;280(2):1641-51; DOI:10.1074/jbc.M407305200

35. Qiu L, Yu H, Liang F. Multiple C2 domains transmembrane protein 1 is expressed in CNS neurons and possibly regulates cellular vesicle retrieval and oxidative stress. J Neurochem. 2015;135(3):492-507; DOI:10.1111/jnc.13251.

36. Abdel-Rahman WM, Lotsari-Salomaa JE, Kaur S, Niskakoski A, Knuutila S, Järvinen H, Mecklin JP, Peltomäki P. The Role of Chromosomal Instability and Epigenetics in Colorectal Cancers Lacking $\beta$-Catenin/TCF Regulated Transcription. Gastroenterol Res Pract. 2016;2016:6089658; DOI:10.1155/2016/6089658.

37. Hernandez L, Kim MK, Lyle LT, Bunch KP, House CD, Ning F, Noonan AM, Annunziata CM. Characterization of ovarian cancer cell lines as in vivo models for preclinical studies. Gynecol Oncol. 2016;142(2):332-40; DOI:10.1016/j.ygyno.2016.05.028.

38. Stukova M, Hall MD, Tsotsoros SD, Madigan JP, Farrell NP, Gottesman MM Reduced accumulation of platinum drugs is not observed in drug-resistant ovarian cancer cell lines derived from cisplatin-treated patients. J Inorg Biochem. 2015;149:45-8; DOI:10.1016/j.jinorgbio.2015.05.003.

39. Hamilton TC, Young RC, McKoy WM, Grotzinger KR, Green JA, Chu EW, Whang-Peng J, Rogan AM, Green WR, Ozols RF. Characterization of a human ovarian carcinoma cell line (NIH:OVCAR-3) with androgen and estrogen receptors. Cancer Res. 1983;43(11):5379-89.

40. Kiessling A, Hogrefe C, Erb S, Bobach C, Fuessel S, Wessjohann L, Seliger B. Expression, regulation and function of the ISGylation system in prostate cancer. Oncogene. 2009;28(28):2606-20; DOI:10.1038/ onc. 2009.115 .

41. Iacobuzio-Donahue CA, Maitra A, Olsen M, Lowe AW, van Heek NT, Rosty C, Walter K, Sato N, Parker A, Ashfaq R, Jaffee E, Ryu B, Jones J, Eshleman JR, Yeo CJ, Cameron JL, Kern SE, Hruban RH, Brown PO, Goggins $M$. Exploration of global gene expression patterns in pancreatic adenocarcinoma using cDNA microarrays. Am J Pathol. 2003;162(4):1151-62; DOI:10.1016/S0002-9440(10)63911-9.

42. Desai SD, Reed RE, Burks J, Wood LM, Pullikuth AK, Haas AL, Liu LF, Breslin JW, Meiners S, Sankar S. ISG15 disrupts cytoskeletal architecture and promotes motility in human breast cancer cells. Exp Biol Med (Maywood). 2012;237(1):38-49; DOI:10.1258/ebm.2011.011236.

43. Andersen JB, Aaboe M, Borden EC, Goloubeva OG, Hassel BA, Orntoft TF Stage-associated overexpression of the ubiquitin-like protein, ISG15, in bladder cancer. Br J Cancer. 2006;94(10):1465-71; DOI:10.1038/ sj.bjc.6603099.

44. Wang Y, Ding Q, Xu T, Li CY, Zhou DD, Zhang L. HZ-6d targeted HERC5 to regulate p53 ISGylation in human hepatocellular carcinoma. Toxicol Appl Pharmacol. 2017;334:180-191; DOI:10.1016/j.taap.2017.09.011.

45. Tang J, Yang Q, Cui Q, Zhang D, Kong D, Liao X, Ren J, Gong Y, Wu G. Weighted gene correlation network analysis identifies RSAD2, HERC5, and CCL8 as prognostic candidates for breast cancer. J Cell Physiol. 2020;235(1):394-407; DOI:10.1002/jcp.28980.

46. Marín-Aguilera M, Codony-Servat J, Kalko SG, Fernández PL, Bermudo R, Buxo E, Ribal MJ, Gascón P, Mellado B. Identification of docetaxel resistance genes in castration-resistant prostate cancer. Mol Cancer Ther 2012;11(2):329-39; DOI:10.1158/1535-7163.MCT-11-0289. 
47. Hou DL, Chen L, Liu B, Song LN, Fang T. Identification of common gene networks responsive to radiotherapy in human cancer cells. Cancer Gene Ther. 2014;21(12):542-8; DOI:10.1038/cgt.2014.62.

48. Huang C, Wang Y, Huang JH, Liu W. Sema3A drastically suppresses tumor growth in oral cancer Xenograft model of mice. BMC Pharmacol Toxicol. 2017 Jul 6;18(1):55; DOI:10.1186/s40360-017-0163-4.

49. Abukhdeir AM, Park BH. P21 and p27: roles in carcinogenesis and drug resistance. Expert Rev Mol Med. 2008;10:e19; DOI:10.1017/ S1462399408000744.

50. Świerczewska M, Sterzyńska K, Wojtowicz K, Kaźmierczak D, Iżycki D, Nowicki M, Zabel M, Januchowski R. PTPRK Expression Is Downregulated in Drug Resistant Ovarian Cancer Cell Lines, and Especially in ALDH1A1 Positive CSCs-Like Populations. Int J Mol Sci. 2019;20(8):2053; DOI:10.3390/ijms20082053. 